\title{
Modeling and Control Analysis of Wind Turbine of Two Bladed and Three Bladed Wind Turbine Systems
}

\author{
L V Suresh Kumar*, Chintu Jaganmohanarao, Sai Lakshmi B \\ GMR Institute of Technology, Rajam, Srikakulam, GMR Nagar 532127, Andhra Pradesh, India \\ Sri Sivani College of Engineering \& Sri Sivani institute of Technology, Srikakulam, Andhra Pradesh, India \\ ${ }^{*}$ Corresponding author, Email: Ivenkatasureshkumar@gmail.com, ch.jagan211@gmail.com, \\ mail2bsai@gmail.com
}

\begin{abstract}
The wind power industries arepresently the fastest raising renewable energy sector throughout the world compare to other sourses. the main aim of this paper is to develop the mathematical model and implemented in simulations for torque control of two bladed and three bladed wind turbine, by changing coefficient of power, tip speed ratio and pitch angle values for different wind speeds. To ensure that an economically competitive wind power making, the trend as to increase the turbine size and while at the same time minimize material usage. Main aim of the paper two cases are developed one for two bladed wind turbine system and another for the three bladed wind turbine system and compared the simulation results of both cases. Finally two balade and three blade systems are mathematically developed and implemented in matlabsimulink.
\end{abstract}

Keywords: pitch angle, LQG controller, tip speed ratio, torque control, wind turbines

Copyright $\odot 2015$ Institute of Advanced Engineering and Science. All rights reserved.

\section{Introduction}

The continuous growth of energy need together with the advantages brought by the utilization of wind turbines, made impetuous the optimization of their functioning. From the control point of view, the problem consists not only on ensuring an optimal operation but also on load reduction and grid integration. Another important challenge is to provide good quality energy delivery from a profoundly irregular primary source of the wind. The characteristics of the wind energy source are important in different aspects regarding wind energy exploitation. The energy available in the wind varies with the cube of the wind speed [1]. The wind is highly variable both in space and in time.

The pitch angle and electromagnetic torque control variables are used to meet specified objectives for Full Load Zone where the contribution to the primary frequency control takes a special interest. The full load zone is the zone where most power is produced from WTs i.e., where the available power in wind is above the WT rated power [2-4]. These control objectives are to reduce structural dynamic loads and to regulate the power produced by the wind turbine. The proposed controller is designed in order to optimize a tradeoff between these objectives [5-13].

An advanced controller could not only ensure desired performances but will help in increasing the lifetime of the turbine and its components and in the same time in reducing the costs necessarily to perform its maintenance $[14,16]$. The LQG collective pitch controller presented in this paper contains an integral action in one loop in addition to a feedforward loop in case of with tracking. The considered wind turbine is an island two- bladed, 400 $\mathrm{KW}$ wind turbine and second one is three bladed wind turbines.

The remainder of this paper is structured as follows. In Section II, a brief introduction to studied wind system. Section III analyzes the control design of wind system. In Section IV analyzes the simulation results of controller of both two cases, Section V concludes the paper.present their articles in the section structure:

\subsection{Wind System}

At present, there are several variable speed wind turbine configurations that are being widely used. For this study, a horizontal variable speed wind turbine was chosen. The 
variable speed wind turbine type is currently the most used technology and it has proven its advantages over the years. The major advantage is that by allowing the rotor to operate at various speeds, one can obtain a more efficient capture of the wind energy with less stress in the turbine drive train during wind gusts [4]. Different wind turbine models are presented. Generally, a model for an entire wind energy conversion system can be structured as several inter connected subsystem models: an aerodynamic, a mechanical, electrical and actuator subsystems. Since the dominant dynamics lie in the mechanical subsystem, special attention will be paid to this aspect.

In this paper, we considered $400 \mathrm{KW}$, two bladed, variable speed and pitch regulated wind turbines as first case and three bladed wind turbines as second case. The main parameters values related to these WTs are given in Table 1 of Appendix [4]. Concerning wind turbines simulation model used in this work takes into account the flexibility of the wind turbines drive-train, with a well known two mass model, as shown in:

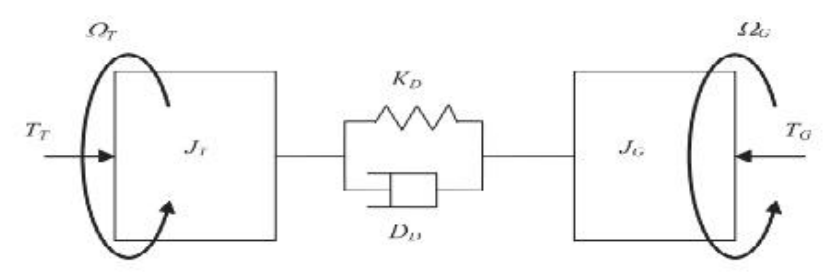

Figure 1. Two-mass Mechanical Model of the drive-train

\begin{tabular}{lc}
\multicolumn{2}{c}{ Table 1. Wind turbine parameters } \\
\hline Name & \multicolumn{1}{c}{ values } \\
\hline Rated power & $\mathrm{P}_{\mathrm{Gnom}}=400[\mathrm{~kW}]$ \\
Nominalrotational speed & $\mathrm{Gnom}=4[\mathrm{rad} / \mathrm{s}]$ \\
Nominal wind speed & $\mathrm{V}_{\mathrm{nom}}=12,25[\mathrm{~m} / \mathrm{s}]$ \\
Blade length & $\mathrm{R}=17[\mathrm{~m}]$ \\
Tower height & $\mathrm{H}_{\mathrm{T}}=48[\mathrm{~m}]$ \\
\hline
\end{tabular}

Thus, it is a simplification of the model described where blades and tower flexibilities are also considered. In Figure $1, \mathrm{~T}_{\mathrm{G}}$ and $\mathrm{T}_{\mathrm{T}}$ are respectively the generator torque and that caught in the wind by the turbine. $T$ and $G$ are the turbine and the generator angular velocities. $J_{T}$ and $J_{G}$ parameters represent the turbine and generator side inertia, while $K_{D}$ and $D_{D}$ are respectively the drive-train stiffness and damping coefficients. Table 2 of the appendices gives these parameters value.

Table 2. Values of the wind turbine model

\begin{tabular}{cc}
\hline parameters & Values \\
\hline$J_{T}$ & $214\left[\mathrm{Tm}^{2}\right]$ \\
$J_{G}$ & $41\left[\mathrm{Tm}^{2}\right]$ \\
$\mathrm{K}_{D}$ & $11,000\left[\mathrm{Tm}^{2} / \mathrm{S}^{2}\right]$ \\
$\mathrm{D}_{\mathrm{D}}$ & $60\left[\mathrm{Tm}^{2} / \mathrm{s}\right]$ \\
$\mathrm{J}_{T}$ & $214\left[\mathrm{Tm}^{2}\right]$ \\
\hline
\end{tabular}

The electric generator of these WTs could be a synchronous or doubly-fed induction machine connected to the farm grid with a full or partial back-to-back converter. The mechanical dynamics of the WTs being much slower and consequently preponderant compared to the electric ones, the generator is here represented as a simple active and reactive power injector. This study has been carried out for this two-bladed $400 \mathrm{~kW}$ WT and three bladed WT working in FL zone. 


\section{LQG CPC Controller Design}

The load alleviation of wind turbine comes to control the electrical power generated by wind turbine to some values depends on grid frequency and on the wind speed. For the contribution to the grid frequency regulation, in $\mathrm{FL}$, rotational speed has to be regulated to its rated value and electrical power has to be controlled depending on the frequency.

The Linear Quadratic Gaussian Collective Pitch Controller (LQG-CPC controller) is designed from its control model, a linear state space representation of the WT [8]. It is composed by a Kalman filter (KF) which calculates the estimate of the state vector from the measurements and the control model. The control model is based on the linearization of the aerodynamic part of the two bladed wind turbine simulation model and three bladed WT model [1]. LQG controller is a combination of kalman filter and linear quadratic regulator (LQR). The block diagram of LQG controller is shown in Figure 2.

The state space equations of LQG controller are obtained from the two mass model can be expressed as:

$$
\begin{aligned}
& =A x+B u+G w \\
Y & =C x+D u
\end{aligned}
$$

In above equations $A$ is state variable matrix, $B$ is control variable matrix, $G$ is input disturbance matrix, $C$ is output matrix and $D$ is output disturbance matrix. Let us assumed that $D$ is zero i.e., there is no output disturbance. $Y$ is the output vector, $x$ is state variable vector and $u$ is control variable vector and $w$ is input disturbance vector.

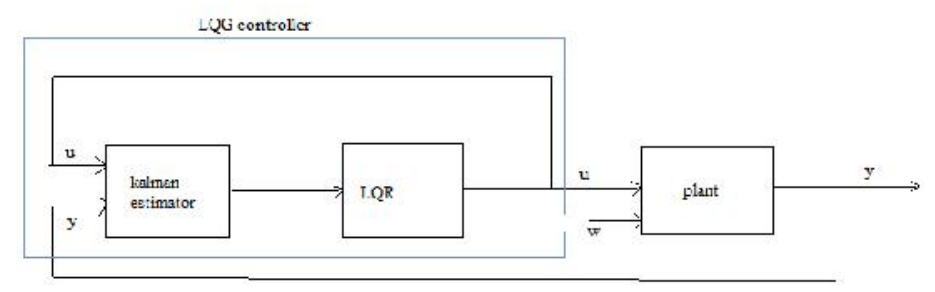

Figure 2. Block Diagram of LQG controller of wind turbine

\subsection{Two Bladed System}

First case is for two bladed wind turbine systems. The state vector $\mathrm{x}$ is composed by the following states:

$$
x=\left(\begin{array}{lllll}
T- & G & T & \beta & V
\end{array}\right)
$$

Where $T-G$ is the twisting angle between the turbine and generator. When these are state variables then the following state representation matrices are obtained:

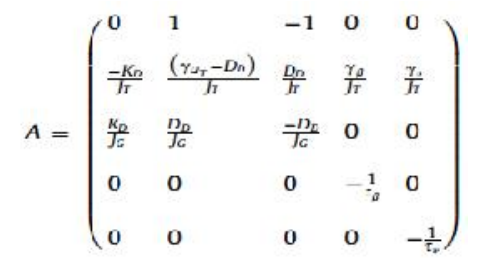

$$
\begin{aligned}
& B=\left(\begin{array}{cc}
0 & 0 \\
0 & 0 \\
\bar{J}_{c}^{1} & 0 \\
0 & \frac{1}{\tau_{\rho}} \\
0 & 0
\end{array}\right) \quad G=\left(\begin{array}{c}
0 \\
0 \\
0 \\
0 \\
\frac{K_{\sigma} \sigma \sigma_{v}}{\tau_{\sigma}}
\end{array}\right)
\end{aligned}
$$


C matrix is written in order to take into account that rotational speed of generator G. by substituting the values of parameters we can get state space matrices for simulation.

\subsection{Three Bladed System}

Second case is for three bladed wind turbine systems. When the first state variable of first case i.e., twisting angle between turbine and generator is changed as $K_{D}(T-G)$ then the obtained state vector for three bladed wind turbines is shown below.

$$
\mathrm{A}=\left(\begin{array}{ccccc}
0 & \mathrm{~K}_{\mathrm{d}} & -\mathrm{K}_{\mathrm{d}} & 0 & 0 \\
\frac{-1}{J T} & \frac{\left(Y_{\mathrm{n} T}-D_{D}\right)}{J T} & \frac{D_{D}}{J T} & \frac{Y_{s}}{J T} & \frac{Y_{v}}{J T} \\
\frac{J}{J G} & \frac{D_{D}}{J G} & \frac{-D_{D}}{J G} & 0 & 0 \\
0 & 0 & 0 & \frac{1}{T_{s}} & 0 \\
0 & 0 & 0 & 0 & \frac{1}{T \mathrm{v}}
\end{array}\right)
$$

The other matrices are same. Now calculating A, B, C, G matrices for to get simulation circuit of LQG controller. Here we assume that there is no output disturbance, so $D$ matrix is zero.

\section{Simulation and results}

The simulation diagram of wind turbine without control for disturbance in wind speed is shown in below Figure 3. The simulink block diagram of LQG controller is shown below Figure 4 with references to the equations.

The control objective make perturbations in the rotor speed as small as possible in order to attenuate the wind disturbance [4]. The different wind disturbances used for this paper are shown in below Figure 5 and 6.

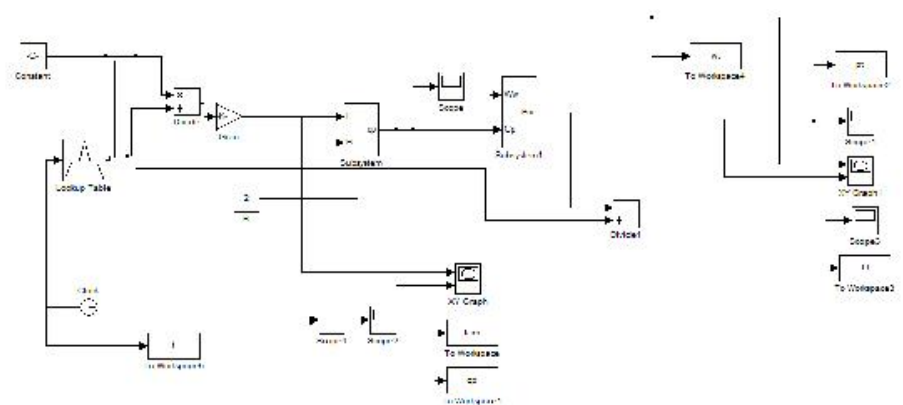

Figure 3. Wind turbine system with no control loop for small step wind disturbance

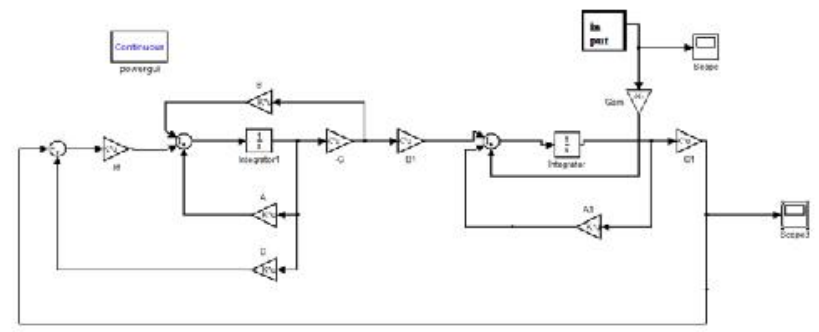

Figure 4. Simulink block diagram of LQG controller

The tip speed ratio and power coefficient graphs for different pitch angles for first type of wind disturbance for two bladed wind turbine systems. This will show in below Figure 5. From 
this we have conclude that by increasing pitch angle value, the power coefficient will decrease. So that control performance depends on pitch angle also.

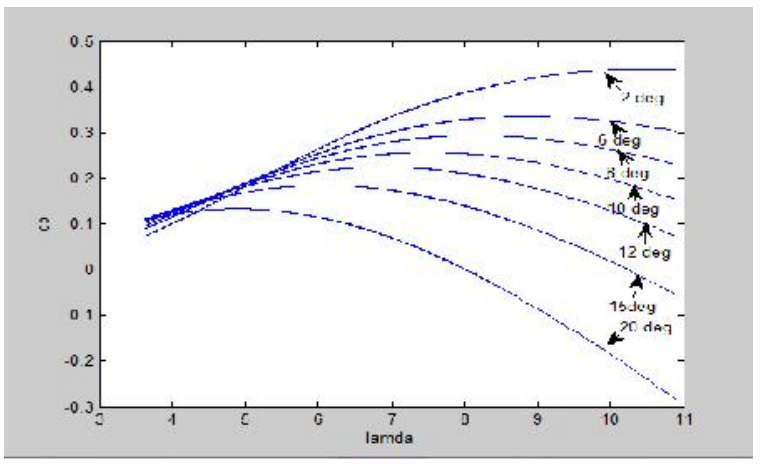

Figure 5. Tip speed ratio versus power coefficient curves

For the first type of wind disturbance, the mechanical power output is obtained for 2 degrees of pitch angle is as shown in below Figure 6 and the torque wave is shown in below Figure 7.

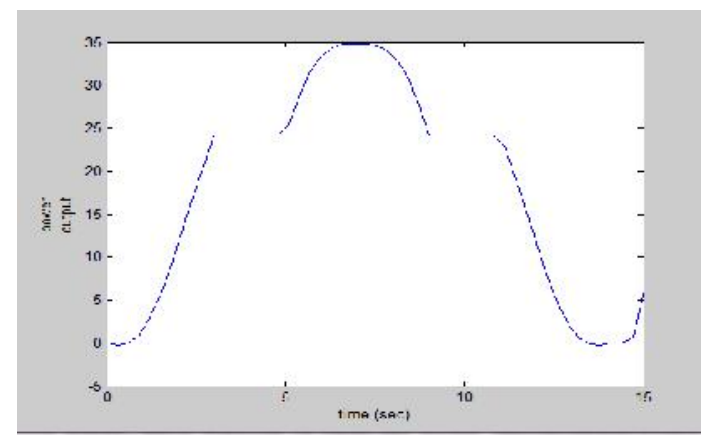

Figure 7. Mechanical power output of wind turbine for first type wind disturbance

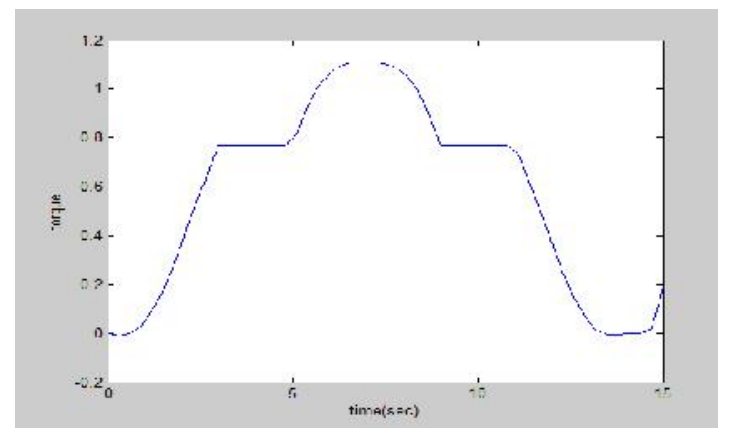

Figure 8. Output torque of wind turbine for first type of wind disturbance

For second type of wind disturbance the output mechanical power and torque wave forms for 2 degrees of pitch angle are shown in below Figure 9 and 10 respectively.

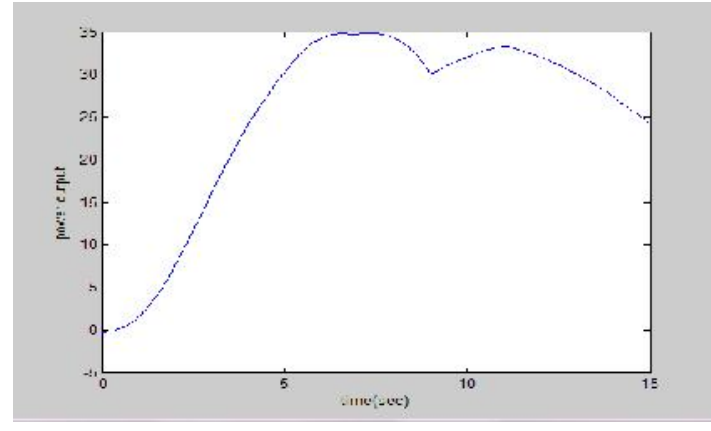

Figure 9. Mechanical power output of wind turbine for first type wind disturbance

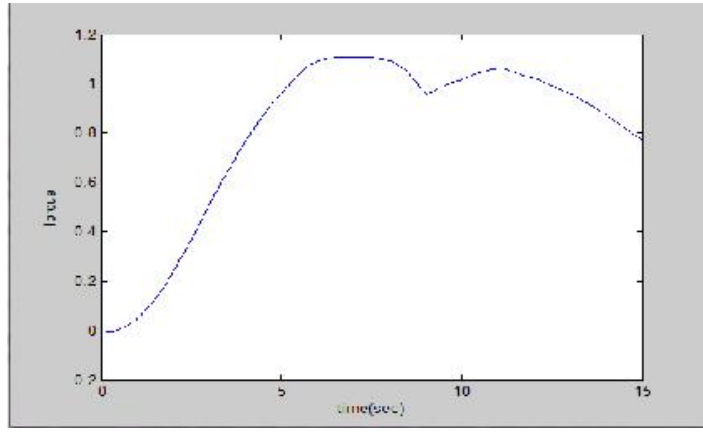

Figure10. Output torque of wind turbine for first type of wind disturbance 


\subsection{Two Blade Simulation Results}

First case is for two bladed WT. when we using LQG controller for the above wind turbine which is simulated by using above equations then the stability of the system is understand by us by using pole zero maps, bode plot and root locus curves. The pole zero map for two bladed wind turbine system is shown in below Figure 11. Each of the poles of the transfer function lies strictly in the left half plane then the system is stable. Here all poles lies on left side of imaginary axis so the system is stable.

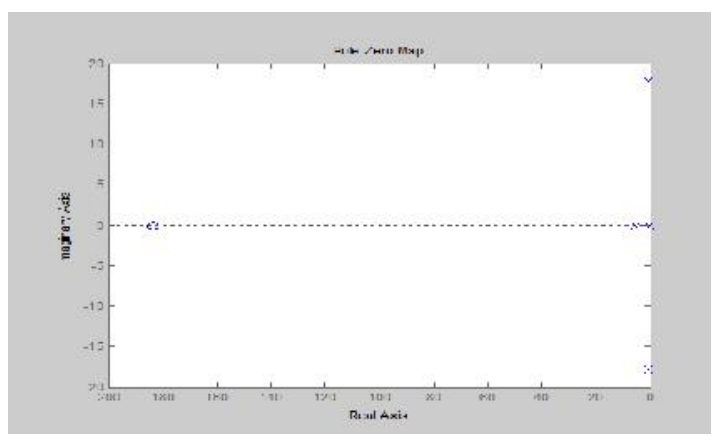

Figure 11. Pole zero map of two bladed wind turbine system

The bode plot of two bladed WT system is shown in below Figure 12. When $\omega_{c}<\omega_{180}$ then the system is stable, where $\omega_{c}$ is the cut off frequency. For this gain margin is infinity and phase margin is -112.2465 .

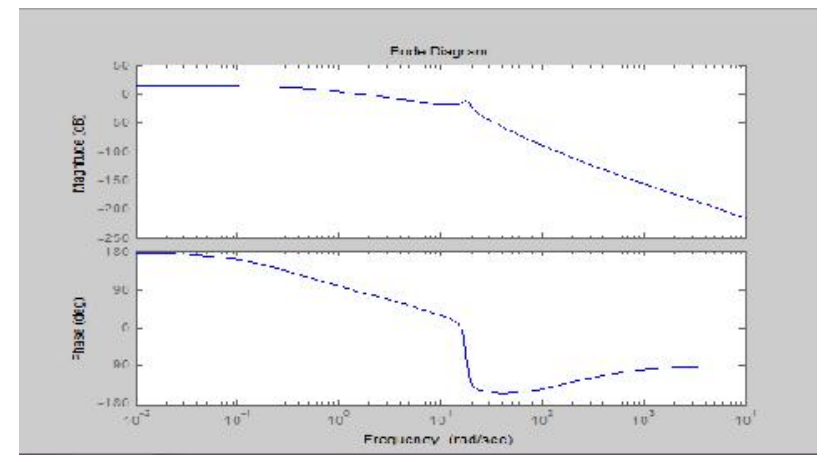

Figure 12. Bode plot for two bladed WT system

The root locus of two bladed WT system is shown in below Figure 13. If the total number of poles and zeros at the right hand side of the segment then the system is stable.

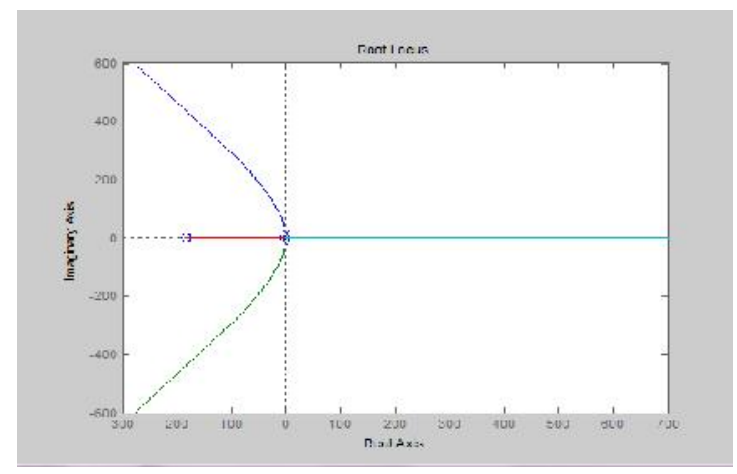

Figure 13. Root Locus of two bladed wind turbine system 


\subsection{Three Bladed Simulation Results}

Second case is for three bladed WT. when we using LQG controller for the above wind turbine which is simulated by using above equations then the stability of the system is understand by us by using pole zero maps, bode plot and root locus curves. The pole zero map for two bladed wind turbine system is shown in below Figure 14.

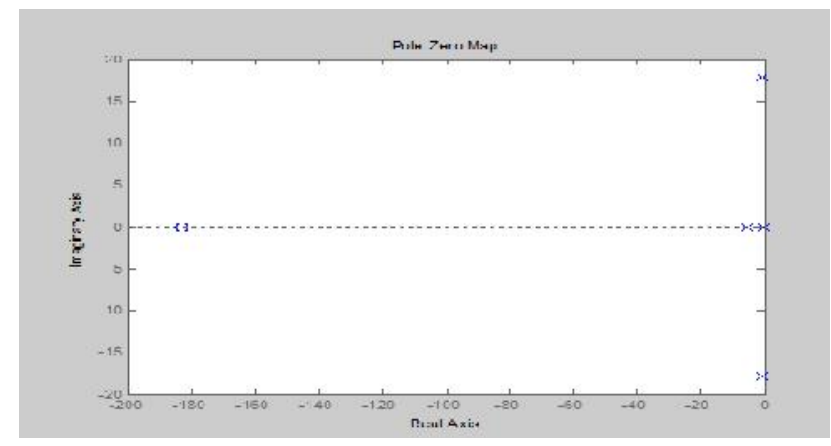

Figure 14. Pole zero map of three bladed wind turbine system

The bode plot of two bladed WT system is shown in below Figure 15. For this gain margin is 0.2050 and phase margin is -93.7778 .

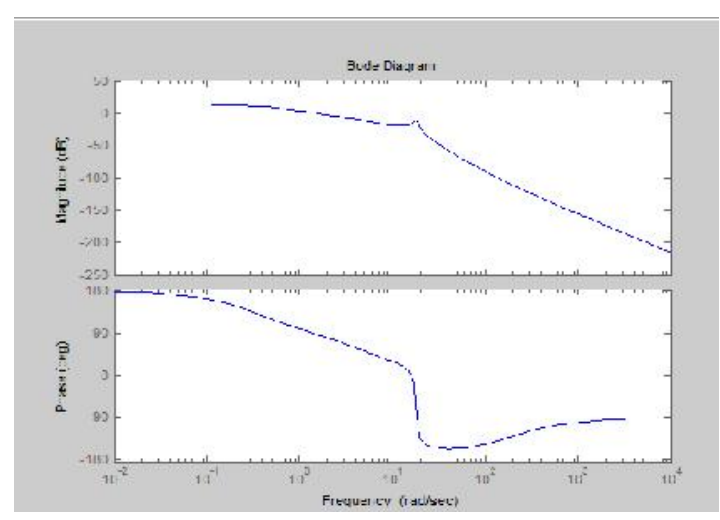

Figure 15. Bode plot for three blade wind turbine system

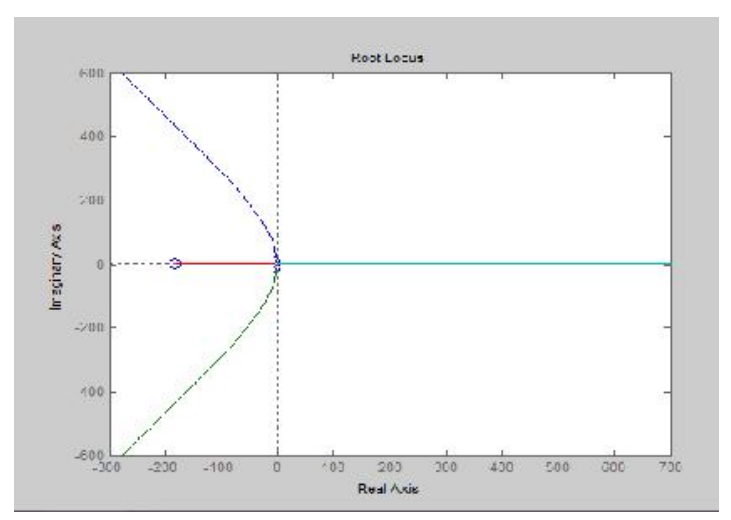

Figure 16. Root Locus of two bladed wind turbine system

\section{Conclusion}

This paper deals with the wind turbine simulation for two bladed and three bladed wind turbine systems. The purpose of this paper is to control the wind turbine output power and torque by controlling the pitch angle. Mainly the paper conclude that power coefficient of wind turbine is controlled by controlling pitch angle. When the pitch angle is increased then the power coefficient of wind turbine is decreased. Comparing both two bladed and three bladed wind turbine systems for different wind disturbances the poles and zeros for both two bladed and three bladed WT are same. Known about when gain margin is greater than phase margin then system is stable. Compared to these systems, both are stable but two bladed WT has infinity gain margin but three bladed WT has 0.2050 . So two bladed WT is more stable than three bladed WT. But control performance is much good for three bladed WT systems. 


\section{References}

[1] Rodriguez-Amenedo JL, Arnalte S, Burgos JC. Automatic generation control of a wind farm with variable speed wind turbines. IEEE Trans Energy Convers. 2002; 17(2): 279-284.

[2] Haritza Camblong' Ionel Vechiu' Xavier Guillaud' Aitor Etxeberria, Stéphane Kreckelbergh. Wind turbine controller comparision an islanding grid in terms of frequency control and mechanical stress. Renewable energy. 2014; 63: 37-45.

[3] Andrew Kusiak, Wenyan Li, Zhe Song. Dynamic control of wind turbine. Renewable energy. 2010; 35(2): 456-463.

[4] Camblong H, Nourdine S, Vechiu I, Tapia G. Comparison of an island wind turbine collective and individual pitch LQG controllers designed to alleviate fatigue loads. IET Renew Power Generation. 2012; 6(4): 267-275.

[5] De Matos JG, SFe Silva F, de S Ribeiro LA. Power Control in AC Isolated Microgrids with Renewable Energy Sources and Energy Storage Systems. Industrial Electronics, IEEE Transactions on. 2015; 62(6): 3490-3498.

[6] D Anusha, LV Suresh Kumar, GV Nageshkumar. Design of Wind Energy System on the Building Tower Applications. IJIRSET. 2015; 4(2): 2319-8753.

[7] Morren J, de Haan SWH, Ferreira JA. Contribution of DG units to primary frequency control. Euro Trans Electr Power. 2006; 16: 507-521.

[8] Ekanayake J, Holdsworth L, Jenkins N. Control of DFIG wind turbines. Power Engineer. 2003; 17(1): 28-32.

[9] Lalor G, Mullane A, O'Malley M. Frequency control and wind turbine technologies. IEEE Transactions Power System. 2005; 20(4): 1905-1912.

[10] Heba S Abd-El Mageed, Hanaa M Farghally, Faten H Fahmy, Mohamed A Abuo-Elmagd. Control and Modelling of PV-Wind Hybrid Energy Sources for Desalination System. TELKOMNIKA Indonesian Journal of Electrical Engineering. 2015: 14(1): 24-33.

[11] Wanga C, McCalley JD. Impact of wind power on control performance standards. International journal Electro Power Energy Systems. 2013; 47: 225-234.

[12] Marin D. Study of the integration of wind power in island grids. Phd dissertation. France: University of Lille; 2006.

[13] Ragnar Eide. Control design for load reduction on wind turbine system. 2011.

[14] EA Bossanyi. The design of closed loop controllers for wind turbines. Wind energy. 2000; (3): 149163.

[15] Haritza Camblong, Ionel Vechiu, Xavier Guillaud, Aitor Etxeberria, Stéphane Kreckelbergh. Wind turbine controller comparison on an island grid in terms of frequency control and mechanical stress. 2013.

[16] LV Sureshkumar, B Sai Lakshmi. Primary frequency control using LQG collective pitch controller in two bladed and three bladed wind turbine systems. International Conference on Innovations in Electrical \& Electronics Engineering (ICIEEE-2014) Guru Nanak Institutions Hyderabad. 2014.

[17] EA Bossanyi. Individual blade pitch control for load reduction. Wind energy. 2003; 6: 119-128.

[18] Marin D, Camblong H, Guillaud X, Rodriguez M. Comparison of wind turbines technical regulations. IEEE ICIT. Bombay, India. 2006; (6): 15-17.

[19] EA Bossanyi. Development of Individual blade pitch control. ESWA conference: The Science of Making Torque from Wind DUWIND Delft University of Technology. 2004: 19-21.

[20] De Almeida GR, Peças Lopes JA. Participation of doubly fed induction wind generators in system frequency regulation. IEEE Transction Power System. 2007; 22(3): 944-950. 